\title{
Creativity, innovation and implementation: Management experience, venture size, life cycle stage, race and gender as moderators
}

\author{
M. Pretorius* and S.M. Millard \\ Respectively Chair in Entrepreneurship and Department of Statistics, \\ University of Pretoria, Pretoria 0002, Republic of South Africa \\ marius.pretorius@up.ac.za \\ M.E. Kruger \\ Tshwane Municipality, Republic of South Africa \\ Received February 2005
}

\begin{abstract}
SMME (small, medium and micro-enterprise) development has been identified by the South African government as a priority in creating jobs. The Global Entrepreneurship Monitor reports low entrepreneurial activity and suggests entrepreneurial education as paramount for improvement. Entrepreneurial skills depend on creativity and innovation as it distinguishes the entrepreneur from the small venture owner. This study empirically investigated the perceptions of small venture owners about their own creativity, their ventures' innovativeness as well as their implementation orientation. While levels of self-evaluation for own creativity and venture innovativeness were high, implementation orientation was low and correlations between them were weak and not significant. Notwithstanding the expectation that high creativity will lead to high innovation and implementation, this article reports otherwise.
\end{abstract}

It was found that number of years management experience, life cycle phase of the venture and race (cultural heritage) but not venture size and gender moderate perception of own creativity. Perception of venture innovativeness was significantly influenced by the life cycle phase of the venture only. Implementation orientation was significantly influenced by the number of years management experience, life cycle phase of the venture, venture size and race but not by gender.

*To whom all correspondence should be addressed.

\section{Introduction}

Researchers of entrepreneurship have been struggling for decades to uncover the primary determinants of new venture survival and success. Entrepreneurial performance results from a combination of industry knowledge, general management skills, people skills and personal motivation (Wickham 2001:55). SMME (small, medium and microenterprise) development has been identified by the South African government as a priority in creating jobs (Nieman 2001:445). However, reports such as the Global Entrepreneurship Monitor and the World Competitiveness Report indicate that South Africans lag behind their counterparts worldwide with 'total entrepreneurial activity' (Foxcroft, Wood, Kew, Herrington \& Segal, 2002) and their ventures measure low on competitiveness. The Integrated Small Business Development Strategy for South Africa (ISBDS, 2005) postulates the low entrepreneurial activity as its core reason for existence.

According to Carrier, Cossette and Verstraete (1999:1) enterprises are required to demonstrate creativity and innovation if they are to survive and flourish in a competitive and increasingly demanding world. In a study by Hills and Shrader (1998:5) it was found that entrepreneurs agreed that creativity was very important in identifying business opportunities. This strengthens the perception that creativity and innovation are major factors in individuals being entrepreneurial and meeting the changing needs that offer new opportunities. Creativity, knowledge and new ideas have become essential in an era where innovative business models enable organisations to get ahead of competitors (Leibold, Voelpel \& Tekie, 2004:62).

Although various definitions of entrepreneurship acknowledge creativity and innovation as key ingredients of entrepreneurship, Carrier (1999:2) found that when one examines the content of existing entrepreneurship courses and programmes it becomes clear that many fail to address the questions of creativity and innovation. Creativity and innovation contain higher levels of subjectivity than finance and marketing and therefore training for creativity and innovation are often avoided in "hard" business training. This is also reported by Van Vuuren (1997: 1).

Important factors in the implementation of innovation might be self-esteem and self-efficacy. Self-esteem refers to the perception of one's self as capable, important, successful and worthy, while self-efficacy pertains to the belief that one has the ability to perform tasks effectively in various achievement situations. People high in generalised selfefficacy predict that they are likely to succeed at task 
performance in a variety of achievement situations (Gardner \& Pierce, 1998:3). It is therefore hypothesised that people with high levels of self-evaluated creativity will have high levels of implementation with regard to innovation.

This study investigates firstly the status of self-perceived creativity; venture innovativeness and implementation orientation to understand their role in the entrepreneurship domain. Secondly, in view of the above, the moderating effects of venture life cycle phase, manager's number of years experience, gender and cultural background on creativity, innovativeness and implementation were investigated, looking for possible pointers for the development of entrepreneurs.

\section{Problem statement and contribution of the study}

Creativity is a key entrepreneurial skill. This article aims to explore the status of entrepreneurial creativity and its relation to innovativeness and implementation orientation in entrepreneurship. The possible moderators of individual creativity, venture innovativeness and implementation are sought in this article.

If the impact of management experience, venture life cycle phase, venture size, race and gender can be clarified, it may open alternative avenues for entrepreneurial training especially to develop more creative and innovative individuals.

\section{Research objectives}

Given the above problem statement, related research objectives were:

- To determine the levels of creativity, venture innovativeness and implementation orientation of venture managers in South Africa.

- To determine whether correlations exist between creativity, venture innovativeness and implementation orientation.

- To determine the impact of management experience, venture size, life cycle stage, race and gender on creativity, venture innovativeness and implementation orientation.

- To identify what the consequences of the above might be for entrepreneurship education.

\section{Entrepreneurship and creativity}

Entrepreneurship is about the pursuit of opportunity (Shaw, 1996:48). Entrepreneurial activity stems from an imbalance between the potentiality of something new and its realisation, that is, the creating of an exploitable opportunity where none existed previously, by one or more individuals (Brazeal \& Herbert, 1999:34). According to Morris and Kuratko (2002:104) creativity is the soul of entrepreneurship because it is required to spot the patterns and trends that define opportunities.
Entrepreneurship is about the creation of a new organisation together with the antecedents to its creation namely scanning the environment for opportunity, the identification of the opportunity to be pursued, evaluation of the feasibility of the new venture and deciding to pursue the opportunity (Carton, Hofer \& Meeks, 1998:4). Two broad dimensions (both related to creativity) of the entrepreneurial process are discernable in the literature:

\section{- Opportunity recognition and information search, and}

\section{- $\quad$ Resource acquisition and business strategies.}

Ulrich (1998:3) defines two distinct dimensions of the entrepreneurial process as creativity and action (initiative) as follows:

- Creativity is the envisioning of a new combination of resources and market realities often through the questioning of conventional wisdom, the discovery of new knowledge regarding market needs, technology, or the availability of vital resources, and/or finding new applications for pre-existing knowledge.

- Action on the other hand, is needed to pursue the vision, to commit to the pursuit of the opportunity, to marshal the necessary approvals and resources to do so, and to manage the effective implementation of the strategy. Vision without action is of little value.

Creativity is clearly part and parcel of the entrepreneurial skills required to successfully start a venture and the origin of the entrepreneurial process (see also Figure 1).

\section{Creativity and innovation}

Creativity is the process, through which invention occurs, in other words, creativity is the enabling process by which something new comes into existence (Amabile in Brazeal \& Herbert, 1999:39). The creative process can be seen as the starting point of innovation, which sets into motion a series of events culminating in the entrepreneurial event. Not all innovations are creative, for some innovations may be implementations of ideas developed by others and adapted for use locally or are minor incremental changes to existing products, services or processes.

With regard to the application of creativity in the entrepreneurship domain, the first step of the process is for the potential entrepreneur to recognise an opportunity to innovate. To recognise an opportunity to innovate, the entrepreneur must participate in a creative activity. After an opportunity is recognised, the entrepreneur must develop alternative courses of action to take advantage of this opportunity. At this point, ideas need to be enhanced, theories explaining the observed opportunities need to be developed, alternatives need to be compared, criteria established, problems defined, and hypotheses and plans formulated (Amabile, 1998:4). Next, the various alternatives, hypotheses, and plans need to be evaluated and the best one selected for implementation. Finally, the plans need to be implemented, necessitating the skills of the 
accommodator. The entrepreneur must advocate positions or ideas, set objectives, commit to schedules, commit resources, and implement decisions. Amabile (1998:4) identifies three components within individuals that are critical for creativity that can be influenced by managers although the first two are more difficult and time consuming to influence:

- $\quad$ Expertise encompasses everything that a person knows and can do. Expertise requires domain relevant skills and includes all skills relevant to a general domain, rather than skills relevant to only a specific task within a domain, assuming that within a particular domain skills used in any specific task will have a great deal of overlap with skills used in any other task. Domain relevant skills include familiarity with and factual knowledge of the domain in question, facts, principles, opinions about various issues in the domain, knowledge of paradigms, performance guides for solving problems in the domain and aesthetic criteria (Amabile, 1983:69).

- $\quad$ Creative thinking skills refer to how flexibly and imaginatively people approach problems and solutions - their capacity to put existing ideas together in new combinations.

- Motivation determines what people will actually do. Amabile (1998:6) described two types of motivation, namely intrinsic and extrinsic. Extrinsic motivation comes from outside a person, e.g. money. When people are intrinsically motivated, they engage in their work for the challenge and enjoyment of it. The work itself is motivating.

The successful entrepreneurial venture is usually based on a significant innovation. Innovation can be defined as the successful implementation of creative ideas (Brazeal \& Herbert, 1999:36). Innovation is the phase where new ideas are developed and involves the ability to change an idea into a money generating activity. Innovation is seldom a systematic, structured process in the case of the small business enterprise. The point origin of innovation is creativity. Ideas are generated on an ad hoc basis and the business plan is still rough and unfinished. Figure 1 assists in understanding the definitional focuses of creativity and innovation and is based on references used in the text.

In Figure 1 it is shown that innovation is the sum of invention plus the commercialisation of that invention (Ireland, Hitt, Camp \& Sexton, 2001:56). This might be innovation of technological, services and/or managerial nature. According to Jun and Deschoolmeester (2003:4) the entrepreneurs' innovativeness is demonstrated by their willingness and capability to create a paradigm shift in science and technology and/or market structure in an industry from a macro perspective. Creativity therefore appears to be at the origin of innovation and the entrepreneurial process.

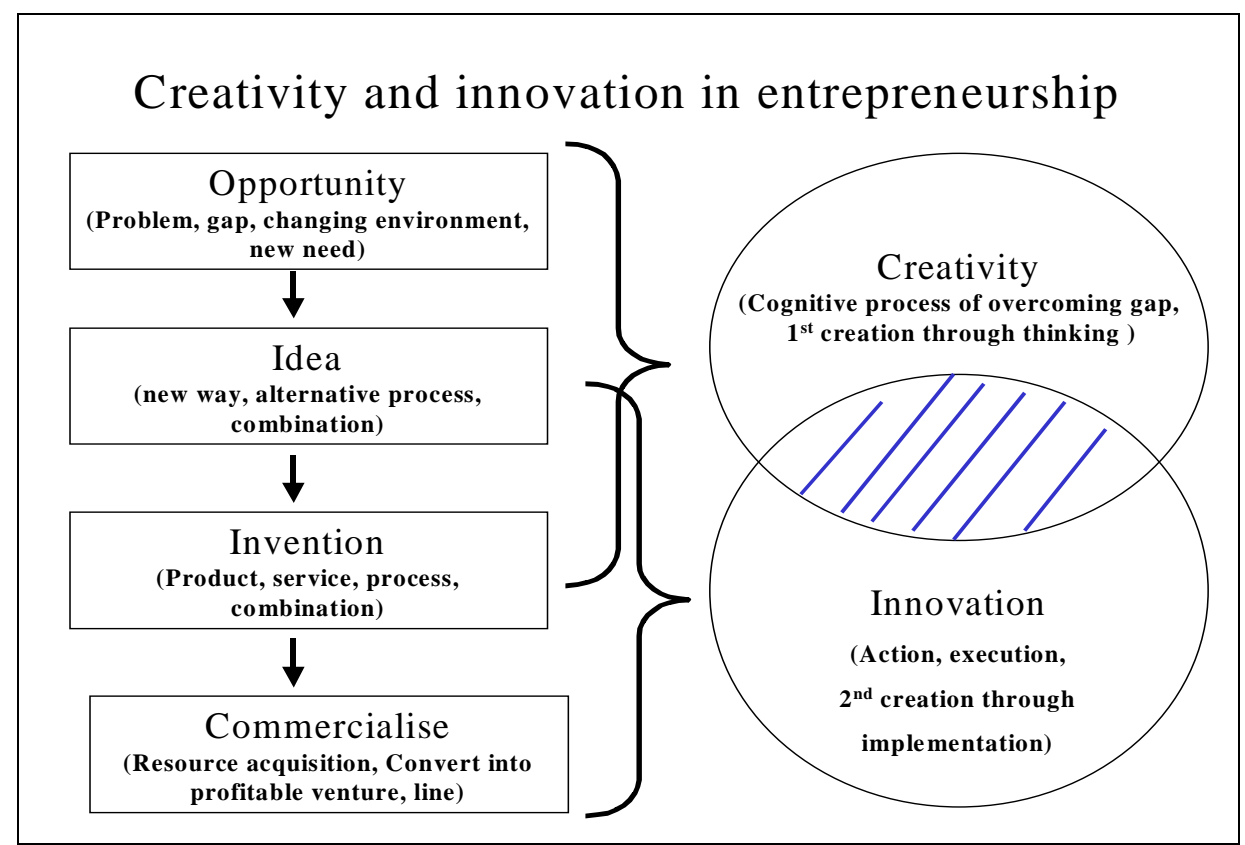

Figure 1: The relation between creativity and innovation indicating the inclusive and distinctive domains between the constructs in entrepreneurship (Own compilation). 


\section{Growth and entrepreneurship}

The size of a venture is a poor guide to whether it is entrepreneurial or not. Nieman and Bennett (2002:63) identify growth as an important factor of entrepreneurship and one that distinguishes the entrepreneurial venture from the small venture. Growth is, inter alia, measured in financial terms such as: turnover; profit; total assets; net assets; net worth and increase in number of employees.

An important concept during the growth phase is change, which is critical for growth, success and stabilisation. There are a number of growth strategies that can be followed (Nieman \& Bennett, 2002:66) such as: generic growth through an increase in the market share, developing new products and/or entering new markets; vertical integration through acquiring firms that are either above or below your own business in the supply chain in a quest for control of supply or marketing; horizontal integration through the acquisition of ventures on the same level, in essence competitors, and lateral integration when the integrated business is neither supplier nor customer or competitor, and the business wishes to diversify to reduce risk or seasonality effects. In all cases of growth, it appears that creative thinking is of value to synthesise alternative ways and new combinations of growing the venture. The role of the individual in this process is the interest of this article.

Wiklund (2001:3) found that business managers' growth intentions are positively related to the actual growth of their ventures. He hypothesised that the level of human capital moderates the relationship between a manager's growth intentions and the level of growth achieved. Growth will therefore increase with intention, but at a faster rate for those with (a) more education, and (b) more relevant experience. It was found however, that the relationship between intention and growth appeared to be more complex than stated. Wiklund (2001:4) is of the opinion that the dynamism of the environment in which the business operated also had an influence.

The entrepreneurial venture usually goes beyond the small business in the objectives it sets itself in that the objectives will be strategic in nature. Strategic behaviour is part of the day-to-day practice of entrepreneurship. In this quest, the managers define a suitable strategy for their enterprises and develop the capabilities to achieve growth (Atac, 2000:2). A strategic position is the way the business as a whole is located relative to competitors in the playing field of the market, that is, the competitive space. Entrepreneurs must therefore be able to decide what stage in the value addition process they expect their ventures to occupy. Selecting a well-defined customer segment enables the business to focus limited resources, to concentrate its efforts, and to defend it against competitors.

The pressure for growth therefore depends more and more on the application of creativity and innovation to find the new opportunities in products, markets and processes.

\section{Creativity and innovation training within entrepreneurship development}

Gibb (1998:4) argues that it is necessary to look at the capacity needed to be a successful entrepreneur. Increasingly there is evidence that the key to effective entrepreneurial behaviour is the development of strategic awareness and orientation (Gibb, 1998:16) and which, as a skill, appears not to be available to everyone. Fayolle (1997:4) is of the opinion that the object of training in entrepreneurship can be defined as provoking the union of an actor- and a project- or process-element. The entrepreneur can be understood in terms of competencies, socio-demographic and psychological characteristics, and behaviours. Experiences with students taught that it was impossible to develop an enterprising spirit and entrepreneurial behaviour, unless an integrated approach was used, balancing the conceptual, instrumental and experimental dimensions. The impact is only really experienced in the long or short term if the student has become fully involved, either individually or collectively, and if phases of experimentation and application have been experienced (Fayolle, 1997:9).

Van Vuuren and Nieman (1999:3) developed a model with three dimensions of entrepreneurial performance stating that $\mathrm{E} / \mathrm{P}=\mathrm{aM} \times \mathrm{bE} / \mathrm{S} \times \mathrm{cB} / \mathrm{S}$. Based on the entrepreneurial performance $(\mathrm{E} / \mathrm{P})$ model, educational programmes are planned to cover the three key constructs of the model. Within the context of any planned programme, different quantities and qualities of skills and knowledge are included. The three elements are shortly described as follows:

- Motivation (M) - The development of performance motivation of the entrepreneur is advised for incorporation in all programmes, proposing that it contributes towards qualities such as inner control, persistence, leadership, decisiveness, determination and shear guts. The associated skills include specifically the development of achievement imagery.

- $\quad$ Entrepreneurial skills (E/S) - Included in this category are various creativity, risk taking and opportunity identification skills.

- $\quad$ Business skills (B/S) - This category covers skills such as financial, marketing, operational, human resource, legal, communication, management and business plan compiling skills.

Pretorius and Van den Berg (2002:203) indicate that creativity education to develop entrepreneurial skills should include: techniques for facilitating creativity, removing barriers to be creative, critical thinking development and creative thinking, personal attributes and actions that facilitate creativity, improving intuitive creativity, creative problem solving and opportunity finding, including opportunity delineation and the generation of ideas and evaluating and prioritising ideas. 
Antonites (2003) in his creativity, innovation and opportunity finding (CIO) action-learning model, emphasises thinking through reflection and action, supported by experience. The background of the model he proposed is based on the work of Vroom in his well-known expectancy theory of motivation. This theory eventually proved that performance can be seen as a multiplicative function of the individual's motivation times his/her abilities $\mathrm{P}=\mathrm{f}(\mathrm{M} \times \mathrm{A})$. Abilities are seen as existing and acquired knowledge (Van Vuuren \& Nieman, 1999:4).

Pretorius, Nieman and Van Vuuren (2005) propose an enhanced entrepreneurial education model where education for entrepreneurial performance $(\mathrm{E} / \mathrm{P})$ is a function of the facilitator's ability and skills (F) to enhance motivation (M), entrepreneurial skills (E/S) and business skills (B/S) through the creative use of different approaches (A's) and the business plan $(\mathrm{B} / \mathrm{P})$ :

$\begin{array}{lll}\mathrm{E} \text { for } \mathrm{E} / \mathrm{P} & = & \text { aFxbM }[\mathrm{cE} / \mathrm{S} \times \mathrm{dB} / \mathrm{S} \times[\mathrm{eA}+\mathrm{fB} / \mathrm{P}] \\ \mathrm{E} \text { for } \mathrm{E} / \mathrm{P} & = & \begin{array}{l}\text { Education for improved entrepreneurial } \\ \text { performance }\end{array} \\ \mathrm{F} & = & \text { Facilitators ability, skills and experience } \\ \mathrm{M} & = & \text { Motivation } \\ \mathrm{E} / \mathrm{S} & = & \text { Entrepreneurial skills } \\ \mathrm{B} / \mathrm{S} & = & \text { Business skills and knowledge } \\ \mathrm{A} & = & \text { Approaches of learning used } \\ \mathrm{B} / \mathrm{P} & = & \text { Business plan utilisation as an approach } \\ \mathrm{A} \text { to } \mathrm{f} & = & \text { Constants }\end{array}$

Being a mathematical model and as the constructs are multiplicative, there is an indication that the absence of any one of the elements such as motivation, entrepreneurial skills or business skills will lead to zero or extremely low levels of entrepreneurial performance as measured by the involvement and execution of start-up activities by the student. From this section, one can identify the importance of creativity and innovation from the attention it receives during development of entrepreneurial skills in training programmes.

Pretorius (2001) suggests that the facilitator is the key construct and based on his skills, knowledge, experience and methodology application should govern the constructs into a mix (similar to the well known marketing mix). The facilitator as a variable is not only a construct but also governs the variable mix and changes it according to varying demands during the programme. Education for E/P therefore, is a function of the facilitator's ability and skills (aF) to enhance motivation (bM), entrepreneurial skills (cE/S) and business skills (dB/S) through the creative use of different approaches (eA's) and specifically the business plan (fB/P).

In summary it is clear that entrepreneurship activity is important and needs development. Key to being entrepreneurial is creativity as it is the antecedent for innovation and strategy to ensure growth. Growth is what distinguishes entrepreneurs and venture managers. Specific attention appears to be required during training and development of entrepreneurial skills. This study endeavours to establish creativity, innovation and implementation levels of small venture managers and to establish how these are impacted by management experience, life cycle stage, size, race and gender.

\section{Methodology}

This study was a cross-sectional study, using the survey method to collect data about the levels and relationships between venture managers' perception of their creative behaviour, their perception of their ventures' innovativeness and their implementation orientation. Innovativeness was measured through the introduction of new products/services, changing of strategic goals and expansion of markets (Kruger, 2004:225) through self-evaluation. Implementation orientation was measured through statements on overcoming barriers and implementation of decisions. Independent variables included years of management experience, venture life cycle stages, venture size, race and gender.

Gaffney's Business Contacts (2002) lists more than 15000 businesses in South Africa and was used as a sampling frame. It must be acknowledged, though, that Gaffney's list, as also other lists of businesses, would include more formalised businesses (those registered for VAT). This possible deficiency was addressed by distributing the mail questionnaire to businesses derived from the above list. The list was supplemented with questionnaires distributed on an ad hoc basis at the Cenbis Business centres in the Tshwane Metropolitan Municipality. Respondents included owners, owner-managers and managers of small ventures. Table 1 describes the sample population in terms of gender, race, business role, business size, years of management experience and venture life cycle phase.

Systematic random sampling was utilised and 650 questionnaires were distributed by mail to potential respondents in the Gauteng area. The mail survey was enhanced by telephonic communication before and during the survey to encourage participation. To address the informal sector, the various business information centres of the City of Tshwane Metropolitan Municipality (CENBIS) distributed an additional 100 questionnaires to business managers that utilised their services on a random basis. Of the 222 returned questionnaires, 218 were completed adequately to analyse the data. This represents a return rate of $29 \%$ that could be considered acceptable for a mail questionnaire compared to the response rate for the South African Innovation Survey, which was in the region of $10 \%$ (Oerlemans, Buys \& Pretorius, 2001:17).

A structured questionnaire (Kruger, 2004:225) with thirty questions (before 'cleaning') was compiled for purposes of this study. A five-point Likert scale where $1=$ strongly disagree, 2 = moderately disagree, 3 = undecided, 4 = moderately agree and 5 = strongly agree was used.

\section{Factor analysis}

The measuring instrument attempted to test perceptions of creativity, venture innovativeness and the implementation orientation of venture managers in South Africa. Given the theoretical indications that there is a degree of 'overlap' among the concepts 'creativity' and 'innovation' in the 
entrepreneurship domain and that the questionnaire had not been used before, confirmation was sought that the instrument indeed tested the three separate constructs.

Factor analysis was conducted to verify whether the dimensions of creativity, innovativeness and the implementation-outcome perceptions represented distinct constructs. Exploratory factor analysis (with BMDP - Direct Oblimin) allows one to test specific propositions about the factor structure for a set of variables. Through selection based on contribution to the Cronbach alphas and the correlation between items within each factor, twenty of the original thirty variables remained. After rotation, the factor analysis suggested the existence of three factors. Oblique rotation was done because of the expected high correlations between the factors. The literature review indicated that a correlation between creativity and innovativeness was to be expected. Calculating the correlation between factors would assist in establishing a possible correlation in South African small venture managers' hypothesised lack of own creativity and their innovative pursuits. In view of the efficacy theory, a low implementation orientation was also expected.

Assuming that the factor analysis model identifies the factors, it should not be expected that the factors would extract all variances from the items but rather only that proportion that is due to the common factors, and shared by several items. In the language of factor analysis, the proportion of variance of a particular item that is due to common factors (shared with other items) is called communality. Communalities as indicated by the squared multiple correlations (co-variances) indicate the amount of variance in each variable that is "explained" by the factors (Cooper \& Schindler, 2001:595). The explained variations by the three factors were $16.99 \%, 6.79 \%$ and $6.52 \%$ respectively for factors one to three (see also Table 2). Investigation of the variables for each factor indicated that three concepts were tested with the questionnaire, namely:

- $\quad$ Factor 1: Perception of own creativity,

- Factor 2: Perception of the business venture's innovativeness,

- $\quad$ Factor 3: Implementation - outcome orientation.

\section{Variance analysis}

In this study some of the constructs did not comply with the requirements for the ANOVA and non-parametric analyses namely Kruskal-Wallis were consequently applied. KruskalWallis test is applied when the base data does not comply with the normal distribution requirement.

\section{Findings and discussions}

Table 1 shows that all race groups are represented in the sample with females only $24,3 \%$ of the sample. Eighty-nine percent of the respondents ranged from micro to medium business that was the main target group namely SMME's. Over $90 \%$ of the sample respondents reported business experience of more than two years with 55,5\% reporting more than 10 years experience. Only $8.7 \%$ reported that they were in the start-up phase indicating that over 92\% were established managers or owners or both. The sample appears to approximate the venture profile of the province though there is no standard to compare with.

\section{Table 1: Demographic information of the sample}

\begin{tabular}{l|c|c}
\hline \multicolumn{1}{c|}{ Factor } & Frequency & Percent (\%) \\
\hline Gender & 165 & 75,7 \\
\hline Male & 53 & 24,3 \\
\hline Female & 73 & 33,5 \\
\hline \multicolumn{2}{|c}{ Social Heritage / Culture / Race } \\
\hline English & 49 & 22,5 \\
\hline Afrikaans & 61 & 27,9 \\
\hline Black South African & 35 & 16,0 \\
\hline $\begin{array}{l}\text { Other (European and } \\
\text { Asian) }\end{array}$ &
\end{tabular}

Business Role

\begin{tabular}{l|c|c}
\hline Owner & 68 & 31,2 \\
\hline Manager & 58 & 26,6 \\
\hline Both & 85 & 39,0 \\
\hline Other (unspecified) & 7 & 3,2
\end{tabular}

Years Business Management Experience

\begin{tabular}{l|c|c}
\hline $0-2$ years & 19 & 8,7 \\
\hline $3-5$ years & 44 & 20,2 \\
\hline $6-10$ years & 34 & 15,6 \\
\hline $10+$ years & 121 & 55,5
\end{tabular}

\begin{tabular}{l|c|c}
\hline \multicolumn{1}{l}{ B+ years } & 121 \\
\hline Business Size & 70 & 32,1 \\
\hline Micro enterprise & 59 & 27,1 \\
\hline Very small business & 39 & 17,9 \\
\hline Small business & 26 & 11,9 \\
\hline Medium business & 24 & 11,0 \\
\hline \multicolumn{2}{|l}{} \\
\hline Barge business & 19 & 8,7 \\
\hline Start-up & 118 & 54,1 \\
\hline Growing & 68 & 31,2 \\
\hline Mature & 13 & 6,0 \\
\hline Declining &
\end{tabular}

Table 2 shows the item analysis for the factors identified through exploratory factor analysis. Variables included had factor loadings above 0,35 and led to the elimination of several variables after "cleaning" to eliminate those that did not load or loaded in more than one factor. Investigation of the variables for each factor confirmed that the three constructs that were measured with the questionnaire were: perception of own creativity, perception of business venture's innovativeness and implementation - outcome orientation respectively.

The scale mean for perception of own creativity was 4,035, indicating that the respondents perceived themselves to be creative with a significant deviation from the midpoint $(p<0,0001)$. The scale mean for perception of venture's innovativeness was 3.798 with a significant difference from the midpoint $(p<0,0001)$ indicating that the venture owners perceived their ventures to be innovative. The reported implementation-outcome orientation however, was not significantly different from the midpoint, namely 2,988. This finding has significant implications for the training and development of entrepreneurs, since the question may be posed whether South African small venture owners would be prepared to undergo training in creativity because they might think that they do not need this kind of training. 
Table 2: Item analysis, correlation matrix and midpoint deviation for the factors

\begin{tabular}{|c|c|c|c|}
\hline & $\begin{array}{c}\text { Factor } 1 \\
\text { (Perception of own } \\
\text { creativity) }\end{array}$ & $\begin{array}{c}\text { Factor } 2 \\
\text { (Perception of venture's } \\
\text { innovativeness) }\end{array}$ & $\begin{array}{c}\text { Factor } 3 \\
\begin{array}{c}\text { (Implementation-outcome } \\
\text { orientation) }\end{array} \\
\end{array}$ \\
\hline Number of items & 9 & 5 & 6 \\
\hline VP (i.e. the variance explained by the factor) & $\begin{array}{c}2,903 \\
16,99 \%\end{array}$ & $\begin{array}{l}1,594 \\
6,79 \%\end{array}$ & $\begin{array}{l}1,414 \\
6,52 \%\end{array}$ \\
\hline Mean & 4,035 & 3,798 & 2,988 \\
\hline Variance & 0,308 & 0,602 & 0,602 \\
\hline Std. Deviation & 0,555 & 0,776 & 0,776 \\
\hline Skewness & $-0,448$ & $-0,500$ & $-0,285$ \\
\hline Kurtosis & 0,099 & 0,019 & $-0,486$ \\
\hline Cronbach Alpha & $\mathbf{0 , 7 9 7}$ & 0,648 & 0,604 \\
\hline Eigenvalue & 4,053 & 2,058 & 1,959 \\
\hline \multicolumn{4}{|l|}{ Factor correlation matrix } \\
\hline Factor 1 & 1,000 & & \\
\hline Factor 2 & $0,266 \mathrm{NS}$ & 1,000 & \\
\hline Factor 3 & $-0,220 \mathrm{NS}$ & $-0,142 \mathrm{NS}$ & 1,000 \\
\hline \multicolumn{4}{|c|}{ Average factor differences from midpoint on scale } \\
\hline Mean deviation from midpoint & 1,034 & 0,789 & 0,012 \\
\hline Standard deviation & 0,556 & 0,777 & 0,777 \\
\hline Wilcoxon P-value for difference & $0,000 * * *$ & $0,000 * * *$ & $0,918 \mathrm{NS}$ \\
\hline
\end{tabular}

The mean perception of venture's innovativeness was lower than the perception of creativity, which might confirm that innovation, however related to creativity is driven by other factors.

Table 2 also indicates the factor correlations for the rotated factors: The correlations indicated weak relationships between the factors. It was indicated that a very high perception of creativity might even result in a negative implementation orientation. This was surprising given the theoretical confirmation that higher and positive correlations between creativity and innovation as well as creativity and implementation orientation was expected based on Bandura’s (1978:238) work.

The mean for perception of venture' innovativeness of 3.798 indicated support that the score on innovativeness of the ventures was lower than that of perceived creativity, and may be an indication that an implementation gap exists.

For implementation orientation, the scale mean was below the midpoint namely 2,9. Of the respondents, $41,7 \%$ indicated that they did not agree with the statements on implementation-outcome orientation, $17,3 \%$ neither strongly agreed, nor disagreed and 41,05\% strongly agreed, therefore no support could be found that South African venture owners do report a high implementation-outcome orientation. Given the high perception of creativity and innovativeness a higher than 2,9 scale mean for implementation outcome-orientation was expected.

\section{Moderating effects of independent variables}

The analysis of variance was applied to identify differences due to the independent variables for the dependent factors identified by the factor analysis, namely perception of own creativity (Table 3), perception of venture's innovativeness
(Table 4) and implementation-outcome orientation (Table $5)$. The independent variables were years of management experience, venture life cycle stage, venture size, race and gender. Figure 2 shows the variable mean variations for the different independent variables.

\section{Years of management experience}

Figure 2 and Tables 3-5 indicate that years of management experience significantly $(p<0,05)$ influences perception of own creativity and implementation orientation but not venture innovativeness. Venture managers with 3-5 years experience perceived themselves to be the most creative with significant differences $(\mathrm{p}<0,05)$ between $3-5$ years and both 5-10 years and 10+ years management experience.

Venture managers with more than 10 years management experience had the highest implementation-outcome orientation while ventures with 0 -2 years experience had the lowest venture innovativeness as well as implementationoutcome orientation. Statistical significant differences were found for implementation orientation between the groups of 0 -2 years' experience versus those with more than 10 years experience and 3-5 years experience versus those with more than 10 years experience. Implementation-outcome orientation increased with years' management experience with the highest among owners with 10 -years+ management experience.

While no differences for perception on venture innovativeness were found amongst respondents with different years' management experience, the group with 3-5 years' experience had the highest response for innovativeness and the group with $0-2$ years' experience the lowest. 


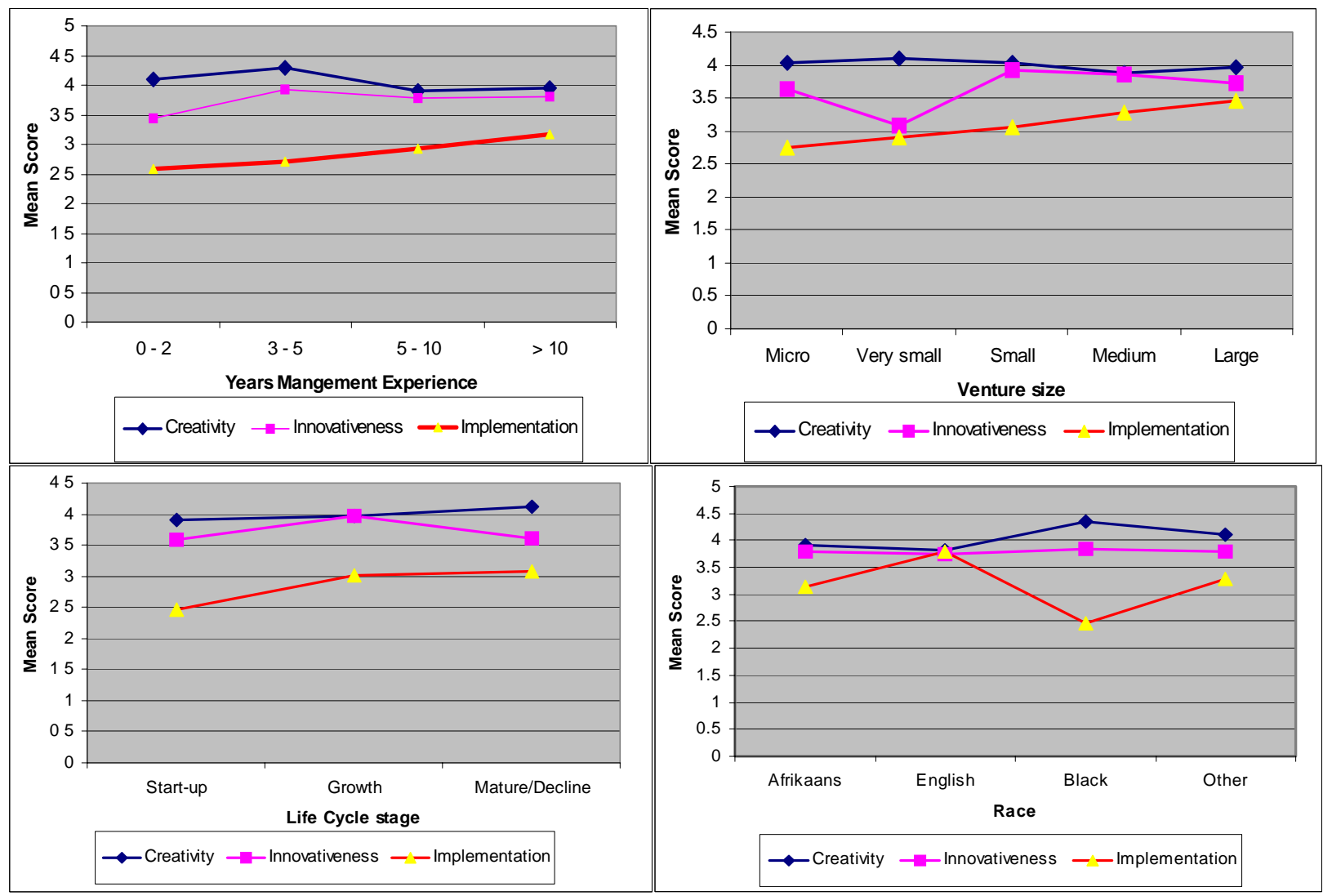

Figure 2: Mean scores for creativity, venture innovativeness and implementation orientation for management experience, life cycle stage, venture size and race

\section{Venture life cycle phase}

Perception of own creativity, venture innovativeness and implementation orientation were all significantly influenced by the life cycle phase of the venture. Perception of creativity was the highest for mature/declining ventures with statistical significant differences $(p<0,05)$ between growing ventures versus mature/declining ventures. This difference was to be expected and came as no surprise. The fact that start-up's did not differ significantly from mature/declining ventures was however surprising and more research is necessary to establish possible reasons for this. It could perhaps be speculated that since research results (Foxcroft et al., 2002) indicate that necessity entrepreneurs constitute $31 \%$ of entrepreneurs in South Africa (a necessity entrepreneur is involved in a new business because they have no other choice of work), are mostly micro and small ventures, the exploration of creative avenues are less important than survival of these ventures.

Venture life cycle phase made a significant difference on how innovative ventures were perceived. In this regard, growing ventures had the highest perceptions of innovativeness and the start-ups the lowest, a finding that was to be expected given to survival focus associated with start-up ventures. Significant differences were found between the "growth" phase and the "mature/declining" phase with regard to perceived venture innovativeness. This difference was expected as it might be ascribed to mature and declining ventures not appearing innovate. This phase is often ascribed to lack of innovation.

\section{Venture size}

No significant differences were observed for perception of own creativity and venture innovativeness based on venture size. Venture size influenced implementation orientation of ventures with micro and very small ventures significantly less able to implement compared to medium and large ventures. There was also a significant difference between very small and large ventures $(\mathrm{p}<0,05)$. Large ventures had the highest implementation-outcome orientation and it can be concluded that implementation orientation might rather be a function of resource availability than the implementation orientation of the venture manager.

\section{Race (Social heritage based on language)}

The South African black languages were grouped together and all other groups (not Afrikaans or English) were pooled together for analysis ('Other' included respondents of European, American and Asian descent). The English language group's perceptions of their own creativity were the lowest of all the groups. Black South African's measured the highest for perception of own creativity differing significantly $(\mathrm{p}<0,05)$ from English and Afrikaans speakers.

Black South Africans' perceptions of their creativeness and their ventures' innovativeness were the highest but their implementation-outcome orientation the lowest. The gap between perception of own creativity and implementation orientation was the biggest for black South Africans. From a 
social psychological perspective, social environment has a significant effect on an individual's motivation, perception and attitudes (Jung, Ehrlich, De Noble \& Baik, 2001:43). The theory that individualistic cultures bring a greater sense of personal responsibility to establish innovative change and performance outcomes (Jung et al., 2001:43), was confirmed by the finding that black South Africans had the lowest implementation-outcome orientation.

No statistical significant differences were found between the various cultural groups for the perception of innovativeness of ventures. Race had a significant influence on implementation-outcome orientation. English respondents reported the highest implementation-outcome orientation. Significant differences were found for the implementationoutcome of the various cultural groups when compared, particularly English vs. Black, Afrikaner vs. Black and Black vs. Other. The English language group's implementation-outcome orientation was significantly $(p<0.05)$ higher than that of Afrikaans speaking respondents as well as Black South African respondents.

\section{Gender}

No significant differences were observed between the genders with implementation orientation tending to be higher for males than females. This might be ascribed to males having better access and support structures to assists in implementation than females (Van der Merwe, 2002:5). Alternatively the higher implementation orientation of males could be due to the fact that females were underrepresented in the sample. Although females perceived themselves to be slightly more creative than males and their ventures more innovative than those of males, their implementationoutcome orientation was lower (not significant).

\section{Conclusions and implications entrepreneurial skills/capacity building}

for

Entrepreneurs have a need to make things happen (implement) to generate income, rather than wait upon the activities and initiatives of others. This reinforces a feeling of total responsibility for the success or failure of the venture, and is, in turn, underpinned by the opportunity, as well as a need, to manage a wide range of tasks and (at least in the early stages of venture) to do everything personally. Klofsten (2000:340) indicates that small venture owners are often sceptical towards organisations offering training and that they are often unaware of what is available on the market and furthermore that they often lack sufficient resources to participate in formal training programmes.

A gap between perceived creativity and implementationoutcome orientation was established through the empirical research in this study. This may indicate a potential lack of self-efficacy (the belief in personal capability to perform a specific task at a specific level of performance) with regard to the entrepreneurial task of innovation. Granted that there are various factors influencing venture performance, namely cognitive approaches, general motives, personal competencies, situational specific motivation, competitive strategies and the business environment (Baum, Locke \&
Smith, 2001:293), it must be acknowledged that several of these have to do with the entrepreneur.

The motivation of the entrepreneur is critical when placed within the entrepreneurial performance perspective (Van Vuuren \& Nieman, 1999). The negative relationship (not significant) between perceived creativity and implementation-outcome in this study might be an indication of some shortcomings in the respondents' motivation and correspondent pro-activeness, which may impact on their openness and readiness for training and development programmes. Addressing entrepreneurs' motivation with regard to their implementation-outcome orientation thus becomes crucial in all training and development programmes, not only creativity and innovation (entrepreneurial skills) but also the business skills.

The moderating effects of race differences for own perceived creativity and implementation open alternative questions. One such question pertains to the possible cultural affects of perception and approach and how it may moderate the relation. Interesting was the English respondents who reported no gap between own creativity and implementation. No apparent reason for this is proposed at this stage.

The higher implementation associated with larger ventures, more management experience and mature life cycle stage is interesting as the question arises whether this is caused by the venture manager's characteristics or is it rather a function of the resources and capabilities of the venture. Given the small percentage of variation explained by the factor $(6.52 \%)$, the resource theory requires more investigation.

In conclusion, this study identified that the sample entrepreneurs see themselves as creative and their ventures as innovative. Unfortunately implementation of creativity and innovation lacks as seen in the lower implementationoutcome orientation. The negative correlation between creativity and implementation (although not significant) opens new research questions.

Gunther and Kirchoff (1998:3) indicate that start-up companies are different in their needs and that according to each different situation, new or changed further education needs and consultation demands may come into existence. These continuing education demands mostly vary. They originate from the entrepreneur's insight in each actual upcoming deficit of his authority concerning capability of acting and deciding, they articulate themselves at that point where mistakes are imminent. Requirements and practical needs arise, concerning persons or enterprises. They neither are to be anticipated, nor to be generalised.

\section{Limitations of the study}

The search for the unique delimitation of creativity in the entrepreneurship domain has only started with this study. In order to develop experiential training and development programmes knowing the 'how' will become critical and unfortunately the creative 'how' of the various 
entrepreneurial activities and tasks has not been described fully as yet.

The underlying dimensions of creativity and innovativeness should have been clarified and better distinguished. This could have contributed towards a better understanding of the various tasks of continuous opportunity exploitation and the creative elements versus the innovative elements and implementation of both these dimensions.

One key limitation of the research is the fact that selfevaluation is regarded as inherently biased. However, it is interesting that the same respondents rate themselves as creative and their ventures as innovative but at the same time low in implementation orientation. This may be ascribed to the fact that the questionnaire items for implementation might have been more indirect than those for creativity and venture innovation. A second possible concern is that perception of venture innovativeness and implementation orientation had Cronbach alphas of lower that 0.70 (despite being above 0.6 ) which may suggest that an attempt to improve the measurement instrument should be pursued for further research. Using the midpoint of the evaluation scale as comparison tool may be seen as a limitation. Lacking any measurement instrument to use at as a standard sparked using the midpoint as point of departure for future research.

\section{Recommendations}

Is it possible then that the age-old problem of implementation is the key to entrepreneurial success and education, rather than the cognitive development of the ideas? It seems that many theoretical answers exist, but if execution lacks, nothing happens. Implementation skills should therefore receive higher priority in the training and development of entrepreneurs.
If continuous venture growth and opportunity exploitation, not only opportunity finding, is seen as core to entrepreneurship, further study and development of models to apply the various modes of creative behaviour, i.e. creation, modification and synthesis in the creative process in the running of a venture, (the activities of strategic planning, resource configuration, marketing as part of the entrepreneurial process), is critical.

To truly develop expertise in a skill, an individual needs multiple and varied experiences - studying the basic characteristics of the skill, experimenting with it, getting coached, and then making improvements and refinements (Conger \& Benjamin, 1999:49). These should be explored in the training process and it is recommended that training and development models be extended to include the experiential application of creativity in the entrepreneurial process, including commercialisation of innovations.

The following alternative development methods can be integrated in the entrepreneurial development process:

- Simulation of business start-up and management processes

- $\quad$ Mentoring/Role Modelling

- Networking (business fraternities, e.g. Business chambers), and

- Linkages (with importers, exporters, buyers etc through trade exhibitions etc.).

It is however crucial that those formal educational institutions take leadership in this regard and lead and manage this entrepreneurial development process within the National Skills Development Framework. 
Table 3: Pair-wise comparison of "perception of own creativity” with independent variables

\begin{tabular}{|c|c|c|c|c|c|c|}
\hline \multirow{2}{*}{\multicolumn{2}{|c|}{ Independent variable }} & \multicolumn{5}{|c|}{ Factor 1: Perception of own Creativity } \\
\hline & & Mean & Std Deviation & $\begin{array}{c}\text { Kruskal- } \\
\text { Wallis test } \\
\text { statistic }\end{array}$ & $\begin{array}{c}\text { Z-stat } \\
\text { (Compared with indep. } \\
\text { variable) }\end{array}$ & $\begin{array}{l}\text { P-value \& } \\
\text { (Significance } \\
\text { Level) }\end{array}$ \\
\hline \multirow[t]{4}{*}{$\begin{array}{l}\text { Number of years } \\
\text { business management } \\
\text { experience }\end{array}$} & (a)0-2 & 4,0994 & 0,5223 & \multirow{4}{*}{11,10} & $\begin{array}{l}\text { (b) } 1,19 \\
\text { (c) } 0,99 \\
\text { (d) } 0,89 \\
\end{array}$ & \multirow{4}{*}{$\begin{array}{c}0,0112 \\
(\mathrm{p}<0,05)\end{array}$} \\
\hline & (b)3-5 & 4,2904 & 0,4981 & & $\begin{array}{l}\text { (c) } 2,68 \\
\text { (d) } 3,11\end{array}$ & \\
\hline & (c)5-10 & 3,9084 & 0,7013 & & (d) 0,33 & \\
\hline & (d)10+ & 3,9669 & 0,5107 & & & \\
\hline \multirow{3}{*}{$\begin{array}{l}\text { Venture life } \\
\text { cycle phase }\end{array}$} & (a)Start-up & 4,1286 & 0,4243 & \multirow{3}{*}{6,89} & $\begin{array}{l}\text { (b) } 0,10 \\
\text { (c) } 1,52\end{array}$ & \multirow{3}{*}{$\begin{array}{c}0,0320 \\
(\mathrm{p}<0,05)\end{array}$} \\
\hline & (b)Growing & 4,1073 & 0,5609 & & (c) 2,52 & \\
\hline & (c)Mature/declining & 3,9067 & 0,5590 & & & \\
\hline \multirow{5}{*}{ Venture Size } & (a)Micro & 4,0428 & 0,6139 & \multirow{5}{*}{3,77} & $\begin{array}{l}\text { (b) } 0,64 \\
\text { (c) } 0,32 \\
\text { (d) } 1,44 \\
\text { (e) } 0,41\end{array}$ & \multirow{5}{*}{$\begin{array}{l}0,4376 \\
\text { (NS) }\end{array}$} \\
\hline & (b)Very Small & 4,1130 & 0,5553 & & $\begin{array}{l}\text { (c) } 0,85 \\
\text { (d) } 1,88 \\
\text { (e) } 0,87\end{array}$ & \\
\hline & (c)Small & 4,0341 & 0,4416 & & $\begin{array}{l}\text { (d) } 1,06 \\
\text { (e) } 0,13\end{array}$ & \\
\hline & (d)Medium & 3,8803 & 0,5153 & & $(\mathrm{e}) 0,82$ & \\
\hline & (e)Large & 3,9861 & 0,5964 & & & \\
\hline \multirow{4}{*}{$\begin{array}{l}\text { Social heritage based } \\
\text { on language }\end{array}$} & (a)Afrikaans & 3,9138 & 0,5329 & \multirow{4}{*}{36,11} & $\begin{array}{l}\text { (b) } 1,06 \\
\text { (c) } 4,15 \\
\text { (d) } 1,72\end{array}$ & \multirow{4}{*}{$\begin{array}{l}<0,0001 \\
(\mathrm{p}<0,01)\end{array}$} \\
\hline & (b)English & 3,8203 & 0,5073 & & $\begin{array}{l}\text { (c) } 5,72 \\
\text { (d) } 2,80\end{array}$ & \\
\hline & (c)Black & 4,3533 & 0,5206 & & (d) 1,96 & \\
\hline & (d)Other & 4,0952 & 0,4955 & & & \\
\hline \multirow{2}{*}{ Gender } & (a)Male & 4,0276 & 0,5404 & \multirow{2}{*}{0,11} & & \multirow{2}{*}{$\begin{array}{c}0,7349 \\
(\mathrm{NS})\end{array}$} \\
\hline & (b)Female & 4,0566 & 0,6084 & & & \\
\hline
\end{tabular}

Table 4: Pair-wise analysis of perception of venture's innovativeness with independent variables

\begin{tabular}{|c|c|c|c|c|c|c|}
\hline \multirow{2}{*}{\multicolumn{2}{|c|}{ Independent variable }} & \multicolumn{5}{|c|}{ Factor 2: Perception of venture's innovativeness } \\
\hline & & Mean & Std Deviation & $\begin{array}{c}\text { Kruskal- } \\
\text { Wallis test } \\
\text { statistic } \\
\end{array}$ & $\begin{array}{c}\text { Z-stat } \\
\begin{array}{c}\text { (Compared with indep. } \\
\text { variable) }\end{array} \\
\end{array}$ & $\begin{array}{c}\text { P-value \& } \\
\text { (Significance level) }\end{array}$ \\
\hline \multirow[t]{4}{*}{$\begin{array}{l}\text { Number of years } \\
\text { business } \\
\text { management } \\
\text { experience }\end{array}$} & (a)0-2 & 3,4316 & 0,5783 & \multirow{4}{*}{6,65} & $\begin{array}{r}\text { (b) } 2,46 \\
\text { (c) } 1,76 \\
\text { (d) } 2,37\end{array}$ & $\begin{array}{l}0,0840 \\
\text { (NS) }\end{array}$ \\
\hline & (b)3-5 & 3,9318 & 0,6540 & & $\begin{array}{l}\text { (c) } 0,76 \\
\text { (d) } 0,52\end{array}$ & \\
\hline & (c)5-10 & 3,7941 & 0,7075 & & (d) 0,42 & \\
\hline & (d)10+ & 3,8082 & 0,8510 & & & \\
\hline \multirow[t]{3}{*}{$\begin{array}{l}\text { Venture life } \\
\text { Cycle phase }\end{array}$} & (a)Start-up & 3,5894 & 0,8013 & \multirow{3}{*}{10,33} & $\begin{array}{l}\text { (b) } 1,95 \\
\text { (c) } 0,22\end{array}$ & $\begin{array}{c}0,0057 \\
(\mathrm{p}<0,01)\end{array}$ \\
\hline & (b)Growing & 3,9678 & 0,6957 & & (c)2,95 & \\
\hline & (c)Mature/ declining & 3,6000 & 0,8336 & & & \\
\hline \multirow[t]{5}{*}{ Venture Size } & (a)Micro & 3,6314 & 0,7732 & \multirow{5}{*}{6,56} & $\begin{array}{l}\text { (b) } 2,22 \\
\text { (c) } 1,96 \\
\text { (d) } 1,28 \\
\text { (e) } 0,61\end{array}$ & $\begin{array}{l}0,1613 \\
\text { (NS) }\end{array}$ \\
\hline & (b)Very Small & 3,0984 & 0,7837 & & $\begin{array}{l}\text { (c) } 0,01 \\
\text { (d) } 0,42 \\
\text { (e) } 1,03 \\
\end{array}$ & \\
\hline & (c)Small & 3,9333 & 0,7641 & & $\begin{array}{l}\text { (d) } 0,38 \\
\text { (e) } 0,95\end{array}$ & \\
\hline & (d)Medium & 3,8615 & 0,7348 & & (e) 0,53 & \\
\hline & (e)Large & 3,7250 & 0,8082 & & & \\
\hline \multirow[t]{3}{*}{$\begin{array}{l}\text { Social heritage } \\
\text { based on language }\end{array}$} & (a)Afrikaans & 3,8040 & 0,7410 & \multirow[t]{3}{*}{0,93} & $\begin{array}{l}\text { (b) } 0,50 \\
\text { (c) } 0,37 \\
\text { (d) } 0,17\end{array}$ & $\begin{array}{l}0,8189 \\
\text { (NS) }\end{array}$ \\
\hline & (b)English & 3,7479 & 0,7378 & & $\begin{array}{l}\text { (c) } 0,95 \\
\text { (d) } 0,27\end{array}$ & \\
\hline & (c)Black & 3,8524 & 0,8389 & & (d) 0,51 & \\
\hline
\end{tabular}




\begin{tabular}{|c|c|c|c|c|c|c|}
\hline & & \multicolumn{5}{|c|}{ Factor 2: Perception of venture's innovativeness } \\
\hline \multicolumn{2}{|c|}{ Independent variable } & Mean & Std Deviation & $\begin{array}{l}\text { Kruskal- } \\
\text { Wallis test }\end{array}$ & $\begin{array}{c}\text { Z-stat } \\
\text { (Compared with indep. }\end{array}$ & $\begin{array}{c}\text { P-value \& } \\
\text { (Significance level) }\end{array}$ \\
\hline & (d)Other & 3,8000 & 0,8231 & & & \\
\hline \multirow[t]{2}{*}{ Gender } & (a)Male & 3,7539 & 0,8150 & \multirow{2}{*}{1,45} & & $\begin{array}{r}0,2280 \\
\text { (NS) }\end{array}$ \\
\hline & (b)Female & 3,9358 & 0,6466 & & & \\
\hline
\end{tabular}

Table 5: Pair-wise analysis of Implementation-outcome orientation with independent variables

\begin{tabular}{|c|c|c|c|c|c|c|}
\hline & & \multicolumn{5}{|c|}{ Factor 3: Implementation - outcome orientation } \\
\hline \multicolumn{2}{|l|}{ Independent variable } & Mean & Std Deviation & $\begin{array}{c}\text { Kruskal-Wallis } \\
\text { test } \\
\text { statistic } \\
\end{array}$ & $\begin{array}{c}\text { Z-stat } \\
\text { (Compared with ind. } \\
\text { variable) }\end{array}$ & $\begin{array}{c}\text { P-value \& } \\
\begin{array}{c}\text { (Significance } \\
\text { level) }\end{array} \\
\end{array}$ \\
\hline \multirow{4}{*}{$\begin{array}{l}\text { Number of years business } \\
\text { management experience }\end{array}$} & (a)0-2 & 2,5877 & 0,6675 & \multirow{4}{*}{17,43} & $\begin{array}{l}\text { (b) } 0,75 \\
\text { (c) } 1,42 \\
\text { (d) } 3,12\end{array}$ & \multirow{4}{*}{$\begin{array}{l}0,0006 \\
(\mathrm{p}<0,01)\end{array}$} \\
\hline & (b)3-5 & 2,6969 & 0,8127 & & $\begin{array}{l}\text { (c) } 0,89 \\
\text { (d) } 3,21\end{array}$ & \\
\hline & (c)5-10 & 2,9313 & 0,7978 & & (d) 1,86 & \\
\hline & (d)10+ & 3,1721 & 0,7235 & & & \\
\hline \multirow{3}{*}{ Venture life cycle phase } & (a)Start-up & 2,4736 & 0,7033 & \multirow{3}{*}{9,37} & $\begin{array}{l}\text { (b) } 2,75 \\
\text { (c) } 3,04\end{array}$ & \multirow{3}{*}{$\begin{array}{l}0,0092 \\
(\mathrm{p}<0,01)\end{array}$} \\
\hline & (b)Growing & 3,0099 & 0,7766 & & (c) 0,64 & \\
\hline & $\begin{array}{l}\text { (c)Mature/ } \\
\text { declining }\end{array}$ & 3,0761 & 0,7587 & & & \\
\hline \multirow{5}{*}{ Venture Size } & (a)Micro & 2,7500 & 0,8286 & \multirow{5}{*}{20,11} & $\begin{array}{l}\text { (b) } 0,88 \\
\text { (c) } 1,75 \\
\text { (d) } 2,93 \\
\text { (e) } 3,85\end{array}$ & \multirow{5}{*}{$\begin{array}{l}0,0005 \\
(p<0,01)\end{array}$} \\
\hline & (b)Very Small & 2,8983 & 0,7792 & & $\begin{array}{l}\text { (c) } 0,94 \\
\text { (d) } 2,20 \\
\text { (e) } 3,11\end{array}$ & \\
\hline & (c)Small & 3,0683 & 0,6030 & & $\begin{array}{l}\text { (d) } 1,28 \\
\text { (e) } 2,16 \\
\end{array}$ & \\
\hline & (d)Medium & 3,2756 & 0,7362 & & (e) 0,84 & \\
\hline & (e)Large & 3,4583 & 0,6298 & & & \\
\hline \multirow{4}{*}{$\begin{array}{l}\text { Social heritage based on } \\
\text { language }\end{array}$} & (a)Afrikaans & 3,1360 & 0,6784 & \multirow{4}{*}{35,43} & $\begin{array}{l}\text { (b) } 0,26 \\
\text { (c) } 4,14 \\
\text { (d) } 0,54\end{array}$ & \multirow{4}{*}{$\begin{array}{l}<0,0001 \\
(\mathrm{p}<0,01)\end{array}$} \\
\hline & (b)English & 3,7894 & 0,6194 & & $\begin{array}{l}\text { (c) } 5,15 \\
\text { (d) } 0,34\end{array}$ & \\
\hline & (c)Black & 2,4617 & 0,7456 & & (d) 4,55 & \\
\hline & (d)Other & 3,2761 & 0,8459 & & & \\
\hline \multirow{2}{*}{ Gender } & (a)Male & 3,0475 & 0,7637 & \multirow{2}{*}{1,45} & & \multirow{2}{*}{$\begin{array}{r}0,2280 \\
(\mathrm{NS}) \\
\end{array}$} \\
\hline & (b)Female & 2,8019 & 0,7986 & & & \\
\hline
\end{tabular}

\section{References}

Amabile, T.M. 1998. 'How to kill creativity', Harvard Business Review, 76(5):76-87.

Amabile, T.M. 1983. The social psychology of creativity. New York: Springer-Verlag.

Antonites, A.J. 2003. 'An action learning approach to entrepreneurial creativity, innovation and opportunity finding'. Unpublished thesis for D Com. Business Management, University of Pretoria, Pretoria.

ATAC, O.A. 2000. Developing strategy for competitiveness. Geneva: International Trade Centre. (Foundation programme in international business management.)

Bandura, A. 1978. 'Reflections on self-efficacy'. In Rachman, S.J. Advances in behaviour research and therapy. Oxford: Pergamon. Elsevier. pp 237-269.
Baum, J.R., Locke, E.A. \& Smith, K.G. 2001. 'A multidimensional model of venture growth', Academy of Management Journal, 44(2):292-303.

Brazeal, D.V. \& Herbert, T.T. 1999. 'The genesis of entrepreneurship', Entrepreneurship theory and practice, 23(3):29-45.

Carrier, C. 1999. 'Teaching creativity, innovation and entrepreneurship: On the necessity for new pedagogical paradigms'. In Raffa, M. (Ed.). Naples, Proceedings of the $44^{\text {th }}$ Annual Conference of the International Council for Small Business, Italy.

Carrier, C., Cossette, P. \& Verstraete, T. 1999. 'Experimental implementation of a new creative method to support futurology by small business in a strategic management perspective'. In Raffa, M. (Ed.).Proceedings of the $44^{\text {th }}$ Annual Conference of the International Council for Small Business, Naples, Italy. 
Carton, R.B., Hofer, C.W. \& Meeks, M.D. 1998. The entrepreneur and entrepreneur-ship: Operational definitions of their role in society. [online] URL: http://www.sbaer.uca.edu/research/1998/ICSB/k004 htm. Accessed 20 July 2002.

Conger, J.A. \& Benjamin, B. 1999. Building leaders: How successful companies develop the next generation. San Francisco: Jossey-Bass

Cooper, D.R. \& Schindler, P.S. 2001. Business research methods. $7^{\text {th }}$ edition. Boston: McGraw-Hill.

Fayolle, A. 1997. 'Teaching entrepreneurship, outcomes from an innovative experience' In Proceedings of International Entrepreneurship conference, Monterey Bay, California, USA. June 25-27.

Foxcroft, M.L., Wood, E., Kew, J., Herrington, M. \& Segal, N. 2002. Global entrepreneurship monitor: South African Executive Report. Cape Town: University of Cape Town, School of Business Management.

Gaffney's Business contacts. 2002. Johannesburg: Gaffney group.

Gardner, D.G. \& Pierce, J.L. 1998. 'Self-esteem and selfefficacy within the organizational context: An empirical examination', Group and Organization Management, 23(1):48-63.

Gibb, A. 1998. 'Entrepreneurial core capacities, competitiveness and management development in the 21st century'. In Proceedings of Internationalizing Entrepreneurship education and training $8^{\text {th }}$ Annual Conference. Schloss Reichartshausen Oestrich-Winkel, Germany. July 26-28.

Gunter, U. \& Kirchoff, R. 1998. 'Training units for young entrepreneurs: Just in time, permanent, sustainable and close to the regional economy'. In Proceedings of Internationalizing Entrepreneurship Education and Training $8^{\text {th }}$ Annual Conference. Schloss Reichartshausen Oestrich-Winkel, Germany. July 26-28.

Hills, G. E. \& Shrader, R. C. 1998. Successful entrepreneurs' insights into opportunity recognition. [online]

URL:http://ww.babson.edu/entrep/fer/papers98/I/I_A/I_A_t ext htm.

Ireland, R. D., Hitt, M.A., Camp, S.M. \& Sexton, D.L. 2001. 'Integrating entrepreneurship and strategic management actions to create firm wealth', The Academy of Management executive, 15(1): 49-64.

ISBDS. 2005. 'Integrated Small Business Development Strategy 2004 - 2014'. Confidential Government report pre-release.

Ivanyi, A. S. \& Hofer, I. 1999. 'The role of creativity in innovation', Society and economy, 21(4): 994-1006.
Jun, Z. \& Deschoolmeester, D. 2003. 'How to gauge the innovativeness held by an entrepreneur: A conceptually, explanatory framework'. In Proceedings of the $48^{\text {th }}$ Annual Conference of the International Council for Small Business. Belfast. June.

Jung, D.I., Ehrlich, S.B., De Noble, A.F. \& Baik, K.B. 2001. 'Entrepreneurial self-efficacy and its relationship to entrepreneurial action: A comparative stuffy between the US and Korea', Management International, 6(1):41-53.

Klofsten, M. 2000. 'Training entrepreneurship at universities: A Swedish case', Journal of European Industrial Training, 24(6):337-346.

Kruger, M.E. 2004. 'Creativity in the entrepreneurship domain'. Unpublished $\mathrm{PhD}$ thesis in Entrepreneurship, University of Pretoria.

Leibold, M., Voelpel, S.C. \& Tekie, E.B. 2004. 'Managerial levers in cultivating new mental space for business innovation', South African Journal of Business Management, 35(4):61 - 71.

Morris, M.H. \& Kuratko, D.F. 2002. Corporate entrepreneurship: Entrepreneurial development within organizations. Fort Worth: Harcourt College Publishers.

Nieman, G. 2001. 'Training entrepreneurs and small business enterprises in South Africa: A situational analysis', Education and Training, 43(8/9): 445-450.

Nieman, G. \& Bennett, A. 2002. Business management: A value chain approach. Pretoria: Van Schaik.

Oerlemans, L.A.G., Buys, A.J. \& Pretorius, M.W. 2001. 'Research design for the South African Innovation survey'. Paper presented at the International Seminar on the Measurement of Innovation Activities, Pretoria, South Africa, March.

Pretorius, M. 2001. 'A training model to enhance micro and small business start-ups in South Africa'. Unpublished DTech thesis, Pretoria Technikon.

Pretorius, M. \& Van den Berg, L.M.M. 2002. 'Creativity and innovation in entrepreneurship training for higher education: A method perspective at Technikon Witwatersand'. In Proceedings Entrepreneurship in Africa: The Road to freedom. $1^{\text {st }}$ International Conference. Grundling, J \& Olivier, N. (Eds.). Pretoria, 3-4 October.

Pretorius, M., Nieman, G.H. \& Van Vuuren, J.J. 2005. 'Critical evaluation of two models for entrepreneurship education: An improved model through integration', International Journal of Educational Management, 19(5). 413-427.

Shaw, D. 1996. 'Creativity and innovation', Business Quarterly, 61(1):48 - 57.

Ulrich, T.A. 1998. 'Entrepreneurship as a learning process'. In Proceedings of International Entrepreneurship 
conference, $8^{\text {th }}$ Annual Conference. Schloss Reichartshausen Oestrich-Winkel, Germany. July 26-28.

Van der Merwe, M. 2002. 'A study of discrimination against women entrepreneurs when applying for financial assistance'. Unpublished Mphil thesis in Entrepreneurship thesis, University of Pretoria.

Van Vuuren, J.J. 1997 'Entrepreneurship education and training: A prospective content model’. Unpublished, UP: 115.

Van Vuuren, J. \& Nieman, G.H. 1999. 'Entrepreneurship education and training: A model for syllabi design'. In Proceedings of the $44^{\text {th }}$ Annual Conference of the International Council for Small Business, Raffa, M. (Ed.). Naples, Italy. June 20-22.

Wickham, P. A. 2001. Strategic entrepreneurship: A decision-making approach to new venture creation and management. $2^{\text {nd }}$ edition. London: Financial Times/Pitman Publishing.

Wiklund, J. 2001. Growth motivation and its influence on subsequent growth. [online] URL:

www.babson.edu/entrep/fer/babson2001/I/I-I/I_I/i-i htm.

Accessed 15 March 2003. 